\title{
Monitoring the Performance of Alpine Skiers with Inertial Motion Units: Practical and Methodological Considerations
}

\author{
Matej Supej ${ }^{1,2}$ (D) $\cdot \mathrm{H}-\mathrm{C}$ Holmberg ${ }^{2,3,4}$ (i)
}

Received: 30 June 2020 / Accepted: 7 January 2021 / Published online: 25 May 2021

(c) The Author(s) 2021

\begin{abstract}
Although reliable feedback is crucial to improving the performance of competitive alpine skiers, the coach's eye may not be sensitive enough to detect small, but highly significant "mistakes". Monitoring of the performance of alpine ski racers by inertial motion units (IMU) has proven to be of value in this context and here we summarize practical and methodological aspects of this approach. Methodologically, the IMUs employed should combine high sampling frequencies with minimal signal drift. The sensors should be positioned to sense the movement of the bones in a given body segment while being protected as much as possible against impact with the ski gates. The data obtained, often synchronized with input from Global Satellite Navigation Systems (GNSS), are usually refined utilizing advanced biomechanical models and other computerized approaches. In practice, the combination of inertial sensors and GNSS allows accurate monitoring of skiing kinematics (technique) and the movement of the skier's center-of-mass, also allowing analysis of both whole-body vibrations (WBV) and loss of mechanical energy. Presentation of the findings to coaches and athletes can be facilitated by synchronizing them with video recordings. Recent advances in IMU technology, including miniaturization, wireless communication, direct storage of data in the cloud, and processing with artificial intelligence may allow these sensors, in-combination with GNSS, to become real-time virtual alpine ski coaches, perhaps the next step in the development of this sport.
\end{abstract}

Keywords Biomechanics $\cdot$ GPS $\cdot$ GLONASS $\cdot$ Kinematics $\cdot$ IMU $\cdot$ Technique

\section{Introduction}

The performance of competitive ski racers, who must adapt to a variety of slopes and courses under varying conditions of weather and snow using different types of equipment, can be improved in many different ways, both major and minor. In alpine skiing competitions, fractions of a second can separate the winner from second-best [58], so the efficacy of their training is clearly a key determinant of success. In this context, reliable feedback is crucial, but most of their

Matej Supej

Matej.Supej@fsp.uni-lj.si

1 Faculty of Sport, University of Ljubljana, Gortanova ulica 22, 1000 Ljubljana, Slovenia

2 Swedish Winter Sports Research Centre, Mid Sweden University, Östersund, Sweden

3 Department of Physiology and Pharmacology, Biomedicum C5, Karolinska Institutet, Stockholm, Sweden

4 China Institute of Sport and Health Science, Beijing Sport University, Beijing, China coaches must rely on their own visual evaluation, which may not be sensitive enough to detect small, but significant differences in technique.

In this connection, the latest advances in wearable technology can provide detailed information concerning skiing technique, racing tactics (e.g., the choice of trajectory), and performance on-snow, as well as numerous other aspects of alpine skiing, such as the performance of equipment (skis and poles), the occurrence of vibrations and their transmission to the skier's body. Indeed, one study has already highlighted the potential of Global Navigation Satellite Systems (GNSS) in this respect [65]. However, to our knowledge, monitoring of alpine skiers utilizing other wearable technology, such as inertial motion units (IMU), has not yet been characterized in detail.

To date, optical motion capture systems based on video filming remain the golden standard in connection with the three-dimensional kinematic analysis of skiing technique, trajectory and performance. At the same time, IMU systems are being employed more and more extensively for such purposes, not only in connection with performance in 
several sports but also in sports medicine and rehabilitation [67]. IMUs can consist of either a single multi-axis sensor (typically incorporating 3-axes with respect to acceleration, angular velocity and orientation, in total as many as 9-axes), e.g., for analyzing jumping performance $[32,36$, 37], or multiple sensors that record kinematic parameters of the arms, legs and/or entire body during various forms of locomotion [29, 68, 69].

Indeed, due to the difficulties involved in filming outdoors on snow with camcorders (e.g., multiple camcorders must be positioned to provide unobstructed visibility of the skiers from at least two angles and appropriate calibration procedures applied), systems based on IMUs are being applied even more extensively in connection with alpine skiing than with a number of other sports $[3,27,51]$. The major challenges associated with such usage include the necessity of capturing large amounts of complex data on snow (during multiple runs through several gates or over the entire course) in a manner that minimizes post-processing, thereby providing results within a short period of time (in fact, immediately, if possible). In the case of alpine skiing, inertial sensors were first used as a complement to GNSS technology [38] and thereafter to monitor whole-body kinematics [3, $27,51]$ and, later, more specific aspects of performance $[9,12,13,40,53,62,63]$. With inertial sensors, many of the limitations described above can be overcome, but, like all approaches, these also have their limitations (discussed below in the section on methodological considerations).

Clearly, IMU technology provides a tool for monitoring all aspects of skiing technique $[3,51]$, thereby providing a basis for improving performance [16, 46, 49, 59, 60]. At the same time, it is crucial that the feedback provided by this technology is as accurate as possible. Accordingly, this review focuses on the scientific literature presently available that deals with practical and methodological considerations related to the evaluation of competitive skiing with IMU technology. In this respect, the kinematic and kinetic parameters that can be monitored by IMU technology will be discussed in the section on practical considerations; while under methodological considerations, sample size, the validity, reliability and limitations of such sensors, and their use together with supplementary technology will be presented.

\section{Practical Considerations}

Biomechanical analysis of the techniques used by competitive alpine skiers, as well as various other aspects of their performance, is often performed for research purposes, as well as to provide feedback that can both help the athletes improve their performance and lower their risk of injury [17, $19,22,40,42,43,48,49,51,52,57,59,60]$.

\section{Kinematic Parameters}

In general, the coaches of alpine skiers focus on their technique in an attempt to improve performance. Because skiing speeds are high, on average ranging from $54 \mathrm{~km} / \mathrm{h}$ during slalom to $94 \mathrm{~km} / \mathrm{h}$ during downhill skiing [18], even movements of different body segments that are too small for coaches to see can be crucial. The capability to objectively monitor skiing technique, including joint angles, the inclination of the skier and of his/her body segments (e.g., the shank), angular velocities and the positions of different body segments while turning and the movement of the skier's center of mass over a large part of or even an entire course is certainly one of the most important features of IMU sensors [3, 50,51]. This information can be of immense value in connection with attempts to improve skiing technique $[3,27,50,51]$ or, e.g., assessment of the impact of skiing equipment on ski safety [72].

Another important feature of IMU sensors is that they can be worn on the body in a manner that allows measurement of joint angles in all three planes, e.g., flexion-extension, abduction-adduction and internal-external rotation of the knee joint [72]. Although, because of the manner in which Euler angles are calculated [21], such measurements of abduction-adduction and internal-external rotation during skiing on-snow are less accurate than those of flexion-extension, they nonetheless provide valuable information (discussed further in Methodological Considerations). Furthermore, some IMU sensors can be used to target specific joint angles, for example, at the knee, hip and/or trunk [13, 14].

For monitoring skiing technique, IMU sensors on the body are usually synchronized with the GNSS system, which enables accurate positioning of the skier on the course $[3,27,50,51]$. Alternatively, this position can be provided by the IMU sensors themselves if magnets are placed next to the gates, providing overall accuracy and precision of 0.24 and $0.09 \mathrm{~cm}$, respectively [9]. Knowing the position of the skier allows more detailed monitoring of the most important parameters of performance, such as the movement of the center-of-mass (CoM), trajectory of skis, turning radius, timing, speed between the gates and energy losses [16, 44, 45, 49, 59, 60, 70]. Although such parameters can also be monitored with the GNSS system alone [65], the combined use provides more accurate monitoring of the movements of the CoM and skis $[3,11$, $19,27,35,50,51]$, particularly key parameters for evaluating performance, such as turning radius, timing, speed between the gates and energy losses.

Timing is crucial in connection with competitive alpine skiing and must be measured accurately and easily over many sections of the course [54] or even between two 
consecutive gates [57]. With the appropriate placement of strong magnets, IMU sensors can also provide gate-togate times or the time that elapses between any two sections of the course [12]. Usage of GNSS for this purpose is dependent on good signal reception by satellites and is thus less accurate in the vicinity of trees or buildings. With both GNSS [57] and IMU sensors, the multiple comparisons of gate-to-gate times provided enable much more detailed analysis than is possible with the standard usage of photocells.

In addition to the information provided by standard camcorder-based systems, IMU technology enables monitoring of whole-body vibrations (WBV) and the transmission of WBV produced during skiing [10, 15, 40, 53, 62, 63, 66]. By selecting technology in accordance with the ISO 8041 International Standards [25], the WBV acting on the skier can be evaluated on the basis of general recommendations for the exposure of workers to such vibrations (International Standard, ISO 2631-1 [24]). Indeed, WBV were found to pose a potential risk for low-back pain, which is experienced by many alpine skiers [63].

Finally, IMU technology enables the collection of much more data during alpine skiing than can in practice be provided by camcorder-based systems. This more extensive data can be utilized, e.g., for more detailed statistical assessment of parameters connected with turning [72] and to "teach" artificial intelligence [6] to recommend approaches to improving skiing technique [35].

\section{Kinetic Parameters}

Obviously, the forces acting on any object under observation are fundamental kinetic parameters. In principle, IMU sensors do not measure forces directly but instead measure acceleration, among other parameters as clarified above in the introduction [1]. In connection with alpine skiing, 3D kinematic systems utilizing camcorders are often employed to estimate ground reaction forces (GRF) [39, 41, 55, 56, 58]. At the same time, these GRFs have already been determined using appropriate placement of accelerometers [63] and this approach, in particular with the usage of multiple IMU sensors on different body segments, can be expected to become more and more common.

Aerodynamic drag and ski-snow friction exert a profound influence on skiing performance. More specifically, almost $50 \%$ of the difference in the performance of downhill skiers is due to air drag, while in the case of giant slalom the corresponding value is approximately $15 \%[30,64$, 65]. Both camcorder-based systems and GNSS technology have already been shown to measure aerodynamic drag during alpine skiing reliably [33, 64]. Although IMU sensors have not yet been applied for measuring aerodynamic drag, this technology could potentially be used in combination with GNSS to provide a better model of the movement of the CoM or to capture the full-body 3D-kinematics provided also by camcorders, as discussed earlier.

Most energy dissipation is due to ski-snow friction, especially during the performance of the technical disciplines of alpine skiing (i.e., slalom and giant slalom) [64], but direct measurement of this friction is difficult in practice and prone to significant error. For example, comparison of this determination using a differential GNSS to camcorderbased measurement indicated that the former approach has a precision of $42 \mathrm{~N}$, with a mean \pm standard deviation between the two procedures of $1 \pm 96 \mathrm{~N}$. In light of the facts that a) due to involvement of the second-order derivative of time after filtering, camcorder-based estimation of ground reaction forces is already associated with an average error in the precision of approximately $150 \mathrm{~N}$; and b) during a carving turn the average ground reaction forces transverse and parallel to the outer ski range from 17 to $61 \mathrm{~N}$, respectively [31], the applicability of such approaches in connection with competitive skiing is limited. As a good alternative, total energy losses in direct relationship to skiing performance can be monitored in a manner that only requires the firstorder derivative of time $[49,59,60]$.

Since aerodynamic drag is not the major determinant of performance in these technical disciplines [64], this factor should be considered separately from friction. Previous approaches to the evaluation of aerodynamic drag involved subtracting drag-related loss of energy from the total energy losses to obtain the loss of energy due to friction. Instead of camera- or solely satellite-based systems, inertial sensors could be used for this purpose, preferably in combination with a real-time kinematic GNSS system to attain high accuracy over a large area, as some investigators have done previously $[27,50,72]$.

\section{Methodological Considerations}

Although the advantages of utilizing IMU sensors for analysis of alpine skiing are considerable, like all approaches, this one has certain limitations, specifically with respect to sample size, the validity and reliability of measurements, and placement of the sensors.

\section{Sample Size}

One of the major limitations associated with the 3D-kinematic studies on alpine skiing reported to date is the relatively small number of subjects involved [22, 58]. These are sometimes only case studies $[45,47]$ or involve, for example, monitoring of 5-15 skiers performing one or two giant slalom turns $[49,60]$ or a maximum of four slalom turns [16]. IMU sensors can potentially be utilized to monitor large 
numbers of turns, even with respect to full-body 3D-kinematics [3, 27, 51].

Nevertheless, alpine skiing is somewhat special, involving extreme difficulties with respect to performing field measurements on a large number of subjects with the same or comparable skiing conditions for all runs (e.g., the problem of gutters and holes on the ski slope) [28, 61]. To a certain extent, this latter problem can be attenuated by smoothing/maintaining the track between runs. In addition, accurate geodetic GNSS systems can help ensure that the course gates are placed in exactly the same locations on several days in a row [73]. In any case, snow conditions, which can significantly affect the level of friction between the skis and ground [4], length of the course, shape of the turns, speeds, etc., must be carefully monitored, especially when investigating performance $[22,58]$.

\section{Validity and Reliability}

When they first came into use, the drift associated with the collection of 3D body kinematic data by inertial sensorbased systems led the scientific community to question the validity of their measurements. In the worst-case scenario, when a single IMU sensor on a forced pendulum with no filtering is utilized, the drift following $35 \mathrm{~s}$ of swinging at a frequency of 0.5 or $2 \mathrm{~Hz}$ is expected to range from $2.1^{\circ}$ to $4.2^{\circ}$, respectively [51]. More recently, the manufacturers of sensors have begun to employ various types of filtering (e.g., quaternion-based complementary filtering, dynamic optimization) and fusion algorithms (e.g., constraining magnetometer estimates) to minimize or eliminate drift $[5,8]$. For instance, when a IMU suit is used to monitor full-body 3D movement, the biomechanical relationships between body segments can also be used to compensate for drift [34].

Nevertheless, the angle of knee flexion during alpine skiing indicated by sensors was found to differ by $4.9^{\circ} \pm 0.4^{\circ}$ and $0.6^{\circ} \pm 1.0^{\circ}$ for the left and right leg from the same angle as measured by the optical systems considered to be laboratory gold standards [27]. In another investigation, Zhang and colleagues [71] reported that measurements by inertial and optical systems differ most with respect to external/internal rotation and abduction/adduction of the knee, leading these investigators to suggest that these differences were primarily due to differences in the anatomical reference frames utilized by these systems. Moreover, the type of inertial sensor employed was found to be of lesser importance. Furthermore, in another laboratory study with an instrumental gimbal, the errors in measurements of 3D joint kinematics by inertial sensors were demonstrated to be approximately $3^{\circ}$ in all three directions [2].

The producers of inertial motion capture suits provide advice concerning how best to position the sensors on the body to monitor relative movements of body segments and, at the same time, minimize potential artefacts due to sensor movement, e.g., as a consequence of muscle contractions [3, 13, 51, 70]. They also provide instructions about ensuring that the sensors are fixed on the body segments as firmly as possible while minimizing interference with athletic movement/performance. Unfortunately, some of this advice can be difficult to follow in connection with alpine skiing. For example, it is difficult to protect sensors on the shanks and arms against impacts with the gates and, furthermore, because of the tight ski boots, it is practically impossible to place sensors directly on the foot.

On the other hand, according to a review [7], the errors associated with stereophotogrammetry, a golden standard for measurement of full-body 3D kinematics, are quite substantial, even under laboratory conditions. The paper conclude, as other authors also have, that: "minor rotations out of this plane are strongly affected by errors introduced at the anatomical landmark identification level and are prone to misinterpretation". Furthermore, the errors associated with laboratory measurements of rotations and abduction/ adduction angles by stereophotogrammetry appear to be of the same magnitude as the differences between stereophotogrammetry and full-body inertial motion capture [71]. This is one reason why IMU systems are being employed more and more extensively in connection with several sports, as well as with sports medicine and rehabilitation [67].

GRF can be determined with force plates, but these are typically cumbersome and may disturb the ski bindings significantly [31]. On the other hand, determination of GFR with camera-based systems, the golden standard for kinematic measurements in the laboratory, is imprecise, particularly when there are high-frequency oscillations in these forces, as during alpine skiing [31]. Although to our knowledge, usage of IMU sensors to determine GRFs during alpine skiing has not yet been adequately validated, modeling indicates that these sensors may provide better estimations of these forces than camera-based systems. In part, this is because the usage of IMU sensors does not require dual data differentiation, which augments noise considerably, necessitating the filtering of data $[26,55,56]$. In addition, the sampling frequencies associated with the recording of IMU data are sufficiently high to allow high-frequency oscillations in GRF to be monitored.

\section{GNSS in Combination with IMUs}

The full-body 3D kinematic data provided by IMUs alone, usually including the relative movement of body segments during the performance of sports like alpine skiing [3, 27, 51], can be related to the athlete's position by the simultaneous use of a GNSS. When these two approaches are combined, the quality of the GNSS is the primary determinant of the global accuracy of the entire system. Although Real-Time Kinematics GNSS 
systems are the golden standard with respect to alpine skiing [65], when the GNSS system itself is not very precise or satellite visibility is poor, IMUs can provide a valuable complement $[3,38]$.

\section{Synchronization of IMU Measurements with Video Recordings}

When monitoring of full-body kinematics by IMU involves multiple IMU sensors, 3D animation of the human body can be used to provide feedback to the athletes. However, when fewer IMUs are used, it is advisable to facilitate analysis by combining the sensor data obtained with video recording (as is sometimes done with GNSS data [65]), especially since both skiers and their coaches are accustomed to analyzing video recordings. To achieve the full potential of this symbiosis, the IMU monitoring and video recording must be synchronized, which can be accomplished with a variety of devices or simply on the basis of isolated, clearly distinguishable body movements, such as leg squats or hits with the skis to the ground [51].

\section{Additional Limitations and Recommendations}

In addition to the limitations that have already been presented, there are some more worth to mention in connection of using IMUs for monitoring alpine skiing performance. Namely, when using full-body inertial motion capture, a relatively expensive set is still needed to be used and only one skier can be monitored at a time using a single system. Furthermore, to ensure that none of the sensors has moved while ascending on the chairlift or gondola or if jostled while riding the lift, a calibration process before each run is advisable that takes some additional time. To execute a trustworthy full-body calibration procedure and follow the instructions by the manufacturers, it is recommended to build a levelled platform on the start to assure proper calibration. Although IMU sensors are getting smaller, with their weight being as low as $10 \mathrm{~g}$ (e.g. MTx, Xsens Technologies, Enschede, the Netherlands), their distribution over the body and wiring may also have some influence on the performance of elite athletes. On the other hand, even wireless IMU systems exist (e.g. MVN Avida, Xsens Technologies, Enschede, the Netherlands), the technical specifications for such systems are often inferior compared to wired ones and in practice, wireless systems may be prone to more connection problems.

\section{Future Perspectives}

As mentioned prevoiusly, the difference between a first and second place in an alpine skiing race can be no more than one-hundredth of a second [18], so even very small improvements in performance can have a considerable impact on the athlete's success. Nevertheless, our understanding of the determinants of alpine skiing performance is still relatively limited [22] and the use of IMU sensors, most often in combination with GNSS systems [65], has the potential to improve this situation considerably. So far, the use of these systems individually or in combination provides coaches and other experts with a large amount of information concerning different kinematic and kinetic parameters related to performance and skiing technique $[3,20,27,49,51,52,60,64]$. In recent years, there has also been a significant reduction in the size and weight of wearable devices [23], allowing less disruptive and more comfortable monitoring of alpine skiing.

In light of the widespread use of smartphones and enormous increase in the number of iOS and Android sports applications available, we can expect smartphones with built-in or complementary external IMU units to be used more and more extensively in conjunction with GNSS systems to monitor alpine skiing. Such use will be promoted by the development of more user-friendly interaction with measuring equipment, including wireless communication, direct storage of data in the cloud, and processing by artificial intelligence that allows more rapid (perhaps even realtime) and accurate data analysis and feedback [35]. Such systems could result in real-time virtual biomechanical coaches, which may represent the next step in the evolution (revolution) of alpine skiing.

\section{Conclusions}

IMU sensors are being used more and more extensively in connection with research on alpine skiing and have made great contributions to our overall understanding of competitive skiing. They can provide classic 3D kinematic measurements as least as reliably as camcorders. At present, the use of more complex systems consisting of many IMUs is limited mainly to scientific research, but simpler systems are already beginning to replace, at least in part, the use of GNSS systems and, of course, photocells and video cameras by coaches. In addition to monitoring the technique and performance of skiers, IMU technology can also be of considerable value in connection with testing equipment (e.g., skis, ski boots), which is, of course, also closely related to performance.

Gradually, coaches are beginning to use technologies more often, even as these technologies become more complex and capable of providing more detailed and accurate feedback. Perhaps in the near future, advanced technology will be able to perform many of the functions now carried out by alpine skiing coaches, but there is little doubt that 
such technology will become a routine digital/virtual assistant trainer who helps skiers reach the winners' podium in connection with the most elite level of competition, such as the Olympic Games and World Championships.

Acknowledgements We are thankful to several coaches and members of various elite ski teams for feedback concerning the measurements and analyses that we have provided to them.

Author Contributions MS and $\mathrm{HCH}$ contributed to all parts of this work, including conception, design, and writing. Both authors approved the final version of this manuscript for publication.

Funding Open Access funding provided by Mid Sweden University. The study was financially supported by the Swedish Olympic Committe and the Slovenian Research Agency within the research program fund P5-0147 Kinesiology of monostructural, polystructural and conventional sports.

\section{Compliance with Ethical Standards}

Conflicts of interest The authors declare that this research was conducted without any commercial or financial relationships that could be construed as a potential conflict of interest.

Consent for publication The work described has not been published before and is not under consideration for publication anywhere else. The publication has been approved by both authors, as well as by the responsible authorities at the institute where the work has been carried out.

Open Access This article is licensed under a Creative Commons Attribution 4.0 International License, which permits use, sharing, adaptation, distribution and reproduction in any medium or format, as long as you give appropriate credit to the original author(s) and the source, provide a link to the Creative Commons licence, and indicate if changes were made. The images or other third party material in this article are included in the article's Creative Commons licence, unless indicated otherwise in a credit line to the material. If material is not included in the article's Creative Commons licence and your intended use is not permitted by statutory regulation or exceeds the permitted use, you will need to obtain permission directly from the copyright holder. To view a copy of this licence, visit http://creativecommons.org/licenses/by/4.0/.

\section{References}

1. Aroganam G, Manivannan N, Harrison D. Review on wearable wechnology wensors used in consumer sport applications. Sensors. 2019;19(9):1983 https://doi.org/10.3390/s19091983.

2. Brennan A, Zhang J, Deluzio K, Li Q. Quantification of inertial sensor-based 3D joint angle measurement accuracy using an instrumented gimbal. Gait Posture. 2011;34(3):320-3.

3. Brodie M, Walmsley A, Page W. Fusion motion capture: a prototype system using inertial measurement units and GPS for the biomechanical analysis of ski racing. Sports Technol. 2008;1(1):17-28.

4. Colbeck SC. A review of the friction of snow skis. J Sports Sci. 1994;12(3):285-95.
5. Cotton RJ, Rogers J. Wearable monitoring of joint angle and muscle activity. IEEE Int Conf Rehabil Robot. 2019;2019:258-63. https://doi.org/10.1109/icorr.2019.8779538.

6. Cust EE, Sweeting AJ, Ball K, Robertson S. Machine and deep learning for sport-specific movement recognition: a systematic review of model development and performance. J Sports Sci. 2019;37(5):568-600. https://doi.org/10.1080/02640414.2018. 1521769.

7. Della Croce U, Leardini A, Chiari L, Cappozzo A. Human movement analysis using stereophotogrammetry. Part 4: assessment of anatomical landmark misplacement and its effects on joint kinematics. Gait Posture. 2005;21(2):226-37. https://doi.org/10. 1016/j.gaitpost.2004.05.003

8. Dorschky E, Nitschke M, Seifer AK, van den Bogert AJ, Eskofier BM. Estimation of gait kinematics and kinetics from inertial sensor data using optimal control of musculoskeletal models. J Biomech. 2019;95:109278. https://doi.org/10.1016/j.jbiomech.2019. 07.022 .

9. Fasel B, Gilgien M, Sporri J, Aminian K. A new training assessment method for alpine ski racing: estimating center of mass trajectory by fusing inertial sensors with periodically available position anchor points. Front Physiol. 2018;9:1203. https://doi. org/10.3389/fphys.2018.01203.

10. Fasel B, Lechot C, Spörri J, Müller E, Aminian K. Body vibration and its transmission in alpine ski racing. International Symposium on 3d Analysis of Human Movement. 2016.

11. Fasel B, Spörri J, Gilgien M, Boffi G, Chardonnens J, Müller E, Aminian K. Three-dimensional body and centre of mass kinematics in alpine ski racing using differential GNSS and inertial sensors. Remote Sens. 2016;8(8):671. https://doi.org/10.3390/rs808 0671.

12. Fasel B, Spörri J, Kröll J, Müller E, Aminian K. A magnet-based timing system to detect gate crossings in alpine ski racing. Sensors. 2019;19(4):940 https://doi.org/10.3390/s19040940.

13. Fasel B, Spörri J, Schütz P, Lorenzetti S, Aminian K. An inertial sensor-based method for estimating the athlete's relative joint center positions and center of mass kinematics in alpine ski racing. Front Physiol. 2017;8:850. https://doi.org/10.3389/fphys. 2017.00850

14. Fasel B, Spörri J, Schütz P, Lorenzetti S, Aminian K. Validation of functional calibration and strap-down joint drift correction for computing 3D joint angles of knee, hip, and trunk in alpine skiing. PLoS ONE. 2017;12(7):e0181446. https://doi.org/10.1371/journ al.pone.0181446.

15. Federolf P, Von Tscharner V, Haeufle D, Nigg B, Gimpl M, Müller E. Vibration exposure in alpine skiing and consequences for muscle activation levels. In: Müller SL E, Stöggl T, editors. Science and skiing IV. Maidenhead: Meyer \& Meyer (UK) Sport Ltd, Aspen Snowmass; 2009. pp. 19-25.

16. Federolf PA. Quantifying instantaneous performance in alpine ski racing. J Sports Sci. 2012;30(10):1063-8. https://doi.org/10.1080/ 02640414.2012.690073.

17. Gilgien M, Crivelli P, Spörri J, Kröll J, Müller E. Characterization of course and terrain and their effect on skier speed in World Cup alpine ski racing. PLoS ONE. 2015;10:e0118119. https://doi.org/ 10.1371/journal.pone.0118119.

18. Gilgien M, Reid R, Raschner C, Supej M, Holmberg HC. The training of Olympic alpine ski racers. Front Physiol. 2018;9:1772. https://doi.org/10.3389/fphys.2018.01772.

19. Gilgien M, Spörri J, Chardonnens J, Kröll J, Limpach P, Müller E. Determination of the centre of mass kinematics in alpine skiing using differential global navigation satellite systems. J Sport Sci. 2015;33(9):960-9. https://doi.org/10.1080/02640414.2014. 977934. 
20. Gilgien M, Spörri J, Chardonnens J, Kröll J, Müller E. Determination of external forces in alpine skiing using a differential global navigation satellite system. Sensors. 2013;13(8):9821-35.

21. Grood ES, Suntay WJ. A joint coordinate system for the clinical description of three-dimensional motions: application to the knee. J Biomech Eng. 1983;105(2):136-44.

22. Hébert-Losier K, Supej M, Holmberg HC. Biomechanical factors influencing the performance of elite alpine ski racers. Sports Med. 2014;44(4):519-33. https://doi.org/10.1007/s40279-013-0132-z.

23. Heikenfeld J, Jajack A, Rogers J, Gutruf P, Tian L, Pan T, Li R, Khine M, Kim J, Wang J, Kim J. Wearable sensors: modalities, challenges, and prospects. Lab Chip. 2018;18(2):217-48. https:// doi.org/10.1039/c7lc00914c.

24. ISO 2631-1. Mechanical vibration and shock. Evaluation of human exposure to whole-body vibration. Part 1: General requirements. 2008.

25. ISO-8041. Human response to vibration-measuring instrumentation. 2005.

26. Klous M, Müller E, Schwameder H. Three-dimensional knee joint loading in alpine skiing: a comparison between a carved and a skidded turn. J Appl Biomech. 2012;28(6):655-64.

27. Krüger A, Edelmann-Nusser J. Application of a full body inertial measurement system in alpine skiing: a comparison with an optical video based system. J Appl Biomech. 2010;26(3):516-21.

28. Lešnik B, Axelsson EP, Supej M. Influence of the start number on elite alpine skiing competitors' results. Kinesiol Slov. 2013;27(6):3-24.

29. López-Nava I, Muñoz-Meléndez A. Wearable inertial sensors for human motion analysis a review. IEEE Sensors J. 2016;16(22):7821-34. https://doi.org/10.1109/JSEN.2016.26093 92.

30. Luethi SM, Denoth J. The influence of aerodynamic and anthropometric factors on speed in skiing. Int J Sport Biomech. 1987;3:345-52.

31. Lüthi A, Federolf PA, Fauve M. Oberhofer K, Rhyner HU, Ammann WJ, Stricker G, Schiefermuller C, Schwameder H, Muller E. Determination of forces in carving using three independent methods. In: Müller E, Bacharach D, Klika R, Lindinger S, Schwameder H, editors. Science and Skiing III. Oxford: Meyer \& Meyer Sport; 2005. pp. 96-106.

32. McGinnis RS, Cain SM, Davidson SP, Vitali RV, Perkins NC, McLean SG. Quantifying the effects of load carriage and fatigue under load on sacral kinematics during countermovement vertical jump with IMU-based method. Sports Eng. 2016;19:21-34. https://doi.org/10.1007/s12283-015-0185-3.

33. Meyer F, Le Pelley D, Borrani F. Aerodynamic drag modeling of alpine skiers performing giant slalom turns. Med Sci Sports Exerc. 2012;44(6):1109-15. https://doi.org/10.1249/MSS.0b013 e3182443315.

34. Mohamed Refai MI, van Beijnum B-J, Buurke JH, Saes M, Bussmann JBJ, Meskers CG, van Wegen E, Kwakkel G, Veltink PH. Portable Gait Lab: Zero Moment Point for Minimal Sensing of Gait*. 2019 41st Annual International Conference of the IEEE Engineering in Medicine and Biology Society (EMBC). 2019. pp 2077-2081. https://doi.org/10.1109/EMBC.2019.8857314

35. Nemec B, Petric T, Babic J, Supej M. Estimation of alpine skier posture using machine learning techniques. Sensors. 2014;14(10):18898-914. https://doi.org/10.3390/s141018898.

36. Picerno P, Camomilla V, Capranica L. Countermovement jump performance assessment using a wearable 3D inertial measurement unit. J Sports Sci. 2011;29(2):139-46. https://doi.org/10. 1080/02640414.2010.523089.

37. Setuain I, Martinikorena J, Gonzalez-Izal M, Martinez-Ramirez A, Gómez M, Alfaro-Adrián J, Izquierdo M. Vertical jumping biomechanical evaluation through the use of an inertial sensor-based technology. J Sports Sci. 2016;34(9):843-51. https://doi.org/10. 1080/02640414.2015.1075057.

38. Skaloud J, Limpach P. Synergy of CP-DGPS, accelerometry and magnetic sensors for precise trajectography in ski racing. 16th International Technical Meeting of the Satellite Division of The Institute of Navigation (ION GPS/GNSS 2003). 2003.

39. Spörri J, Kröll J, Fasel B, Aminian K, Müller E. Course setting as a prevention measure for overuse injuries of the back in alpine ski racing: a kinematic and kinetic study of giant slalom and slalom Orthop. J Sports Med. 2016;4:2325967116630719. https://doi.org/ $10.1177 / 2325967116630719$.

40. Spörri J, Kröll J, Fasel B, Aminian K, Müller E. The use of body worn sensors for detecting the vibrations acting on the lower back in alpine ski racing. Front Physiol. 2017;8:522. https://doi.org/10. 3389/fphys.2017.00522.

41. Spörri J, Kröll J, Fasel B, Aminian K, Müller E. Standing height as a prevention measure for overuse injuries of the back in alpine ski racing: a kinematic and kinetic study of giant slalom. Orthop J Sports Med. 2018;6(1):2325967117747843. https://doi.org/10. $1177 / 2325967117747843$.

42. Spörri J, Kröll J, Gilgien M, Müller E. Sidecut radius and the mechanics of turning-equipment designed to reduce risk of severe traumatic knee injuries in alpine giant slalom ski racing. Br J Sports Med. 2016;50(1):14-9. https://doi.org/10.1136/ bjsports-2015-095737.

43. Spörri J, Kröll J, Gilgien M, Müller E. How to prevent injuries in alpine ski racing: what do we know and where do we go from here? Sports Med. 2017;47(4):599-614. https://doi.org/10.1007/ s40279-016-0601-2.

44. Sporri J, Kroll J, Schwameder H, Muller E. The role of path length- and speed-related factors for the enhancement of section performance in alpine giant slalom. Eur J Sport Sci. 2018;18(7):911-9. https://doi.org/10.1080/17461391.2018. 1453870.

45. Spörri J, Kröll J, Schwameder H, Müller E. Turn characteristics of a top world class athlete in giant slalom: a case study assessing current performance prediction concepts. Int J Sports Sci Coach. 2012;7:647-59. https://doi.org/10.1260/1747-9541.7.4.647.

46. Spörri J, Kröll J, Schwameder H, Müller E. The role of path length- and speed-related factors for the enhancement of section performance in alpine giant slalom. Eur Sport Sci. 2018;18(7):911-9. https://doi.org/10.1080/17461391.2018.14538 70.

47. Spörri J, Kröll J, Schwameder H, Schiefermüller C, Müller E. Course setting and selected biomechanical variables related to injury risk in alpine ski racing: an explorative case study. Br J Sports Med. 2012;46(15):1072-7. https://doi.org/10.1136/bjspo rts-2012-091425.

48. Spörri J, Schiefermüller C, Müller E. Collecting kinematic data on a ski track with optoelectronic stereophotogrammetry: a methodological study assessing the feasibility of bringing the biomechanics lab to the field. PLoS ONE. 2016;11(8):e0161757. https://doi. org/10.1371/journal.pone.0161757.

49. Supej M. Differential specific mechanical energy as a quality parameter in racing alpine skiing. J Appl Biomech. 2008;24(2):121-9.

50. Supej M. A step forward in 3D measurements in alpine skiing: a combination of an inertial suit and dGPS technology. In: MüllerSL E, Stöggl T, editors. Science and skiing IV. Maidenhead: Meyer \& Meyer Sport (UK) Ltd, Aspen Snowmass; 2009. pp. 497-504.

51. Supej M. 3D measurements of alpine skiing with an inertial sensor motion capture suit and GNSS RTK system. J Sports Sci. 2010;28(7):759-69. https://doi.org/10.1080/02640411003716934.

52. Supej M. Gate-to-gate synchronized comparison of velocity retrieved from a high-end global navigation satellite system in 
alpine skiing. The 28 International Conference on Biomechanics in Sports. 2012.

53. Supej M. Vibrations in recreational alpine skiing: a pilot study. The Conference proceedings of the 31st International Symposium on Biomechanics in Sport. 2013.

54. Supej M, Cernigoj M. Relations between different technical and tactical approaches and overall time at men's world cup giant slalom races. Kinesiol Slov. 2006;12:63-9.

55. Supej M, Hébert-Losier K, Holmberg HC. Impact of the steepness of the slope on the biomechanics of World Cup slalom skiers. Int J Sports Physiol Perform. 2015;10:361-8. https://doi.org/10.1123/ ijspp.2014-0200.

56. Supej M, Holmberg HC. How gate setup and turn radii influence energy dissipation in slalom ski racing. J Appl Biomech. 2010;26(4):454-64.

57. Supej M, Holmberg HC. A new time measurement method using a high-end global navigation satellite system to analyze alpine skiing. Res Q Exerc Sport. 2011;82(3):400-11. https://doi.org/ 10.1080/02701367.2011.10599772.

58. Supej M, Holmberg HC. Recent kinematic and kinetic advances in olympic alpine skiing: Pyeongchang and beyond. Front Physiol. 2019;10:111. https://doi.org/10.3389/fphys.2019.00111.

59. Supej M, Kipp R, Holmberg HC. Mechanical parameters as predictors of performance in alpine World Cup slalom racing. Scand J Med Sci Sports. 2011;21(6):e72-81.

60. Supej M, Kugovnik O, Nemec B. DGPS measurement system in alpine skiing track and center of mass estimation. In: Jiang Y, Baca A, Zhang H, editors. Proceeding of first joint international pre-olympic conference of sports sciences and sports engineering computer science in sports. Liverpool: World Academic Union; 2008. pp. 120-5.

61. Supej M, Nemec B, Kugovnik O. Changing conditions on the slalom ski course affect competitors' performances. Kinesiology. 2005;37:151-8.

62. Supej M, Ogrin J. Transmissibility of whole-body vibrations and injury risk in alpine skiing. J Sci Med Sport. 2019;22(Suppl 1):S71-s77. https://doi.org/10.1016/j.jsams.2019.02.005.

63. Supej M, Ogrin J, Holmberg HC. Whole-body vibrations associated with alpine skiing: a risk factor for low back pain? Front Physiol. 2018;9:204. https://doi.org/10.3389/fphys.2018.00204.
64. Supej M, Sætran L, Oggiano L, Ettema G, Šarabon N, Nemec B, Holmberg HC. Aerodynamic drag is not the major determinant of performance during giant slalom skiing at the elite level. Scandinavian J Med Sci Sports. 2013;23(1):e38-47.

65. Supej M, Spörri J, Holmberg HC. Methodological and practical considerations associated with assessment of alpine skiing performance using global navigation satellite systems. Front Sports Acts Living. 2020;1:74. https://doi.org/10.3389/fspor.2019.00074.

66. Tarabini M, Saggin B, Scaccabarozzi D. Whole-body vibration exposure in sport: four relevant cases. Ergonomics. 2015;58(7):1143-50. https://doi.org/10.1080/00140139.2014. 961969.

67. Teufl W, Miezal M, Taetz B, Frohlich M, Bleser G. Validity of inertial sensor based 3D joint kinematics of static and dynamic sport and physiotherapy specific movements. PLoS ONE. 2019;14(2):e0213064. https://doi.org/10.1371/journal.pone.02130 64.

68. Walmsley CP, Williams SA, Grisbrook T, Elliott C, Imms C, Campbell A. Measurement of upper limb range of motion using wearable sensors: a systematic review. Sports Med Open. 2018;4(1):53. https://doi.org/10.1186/s40798-018-0167-7.

69. Weygers I, Kok M, Konings M, Hallez H, De Vroey H, Claeys K. Inertial sensor-based lower limb joint kinematics: a methodological systematic review. Sensors (Basel). 2020;20(3):673. https:// doi.org/10.3390/s20030673.

70. Yu G, Jang YJ, Kim J, Kim JH, Kim HY, Kim K, Panday SB. Potential of IMU sensors in performance analysis of professional alpine skiers. Sensors (Basel). 2016;16(4):463. https://doi.org/10. 3390/s16040463.

71. Zhang JT, Novak AC, Brouwer B, Li Q. Concurrent validation of Xsens MVN measurement of lower limb joint angular kinematics. Physiol Meas. 2013;34(8):N63.

72. Zorko M, Nemec B, Babic J, Lesnik B, Supej M. The waist width of skis influences the kinematics of the knee joint in alpine skiing. J Sports Sci Med. 2015;14(3):606-19.

73. Zorko M, Nemec B, Matjačić Z, Olenšek A, Tomazin K, Supej M. Wide skis as a potential knee injury risk factor in alpine Skiing. Front Sports Act Living. 2020. https://doi.org/10.3389/fspor.2020. 00007. 